\title{
Evaluation of Pathogen Reduction Systems to Inactivate Dengue and Chikungunya Viruses in Apheresis Platelets Suspended in Plasma
}

\author{
Li Kiang Tan ${ }^{1 *}$, Sally Lam ${ }^{2 *}$, Swee Ling Low ${ }^{1}$, Fang Hui Tan ${ }^{2}$, Lee Ching Ng $^{1 \#}$, Diana Teo ${ }^{2}$ \\ ${ }^{1}$ Environmental Health Institute, National Environment Agency, Singapore City, Singapore; ${ }^{2}$ Blood Services Group, Health Sciences \\ Authority, Singapore City, Singapore. \\ Email: ${ }^{N g}$ _lee_ching@nea.gov.sg
}

Received January $12^{\text {th }}, 2013$; revised February $13^{\text {th }}, 2013$; accepted March $13^{\text {th }}, 2013$

\begin{abstract}
The risk of blood-borne transmission of infectious diseases has led to an increasing awareness of the need for a safe and effective pathogen reduction technology. This study evaluated the efficacy of 2 pathogen reduction systems to inactivate dengue virus (DENV-2) and chikungunya virus (CHIKV) spiked into apheresis platelets (APLT) concentrates. Double-dose APLT collections $(n=3)$ were split evenly into two units and spiked with $10^{7}$ infectious units of DENV-2 or CHIKV. APLTs samples were assayed for viral infectivity before and after Amotosalen photochemical treatment (PCT) or Riboflavin pathogen reduction treatment (PRT). Viral infectivity was determined by plaque assays. Platelet (PLT) count, $\mathrm{pH}$ and residual S-59 were measured during the storage of 5 days. Amotosalen PCT showed robust efficacy and complete inactivation of both viruses in APLTs, with up to 3.01 and 3.75 log reductions of DENV-2 and CHIKV respectively. At similar initial concentrations, Riboflavin PRT showed complete inactivation of CHIKV with up to $3.73 \log$ reduction, much higher efficacy than against DENV-2 where a log reduction of up to 1.58 was observed. All post-treated APLTs maintained acceptable PLT yields and quality parameters. This parallel study of 2 pathogen reduction systems demonstrates their efficacy in inactivating or reducing DENV and CHIKV in APLTs and reaffirms the usefulness of pathogen inactivation systems to ensure the safety in PLTs transfusion.
\end{abstract}

Keywords: Pathogen Inactivation; Dengue; Chikungunya; Transfusion-Transmitted Disease; Platelets

\section{Introduction}

Arboviruses have increasingly caught world-wide attention in the last decade. Among them, dengue and chikungunya viruses (DENV and CHIKV) are of major international public health concerns with extensive geographical spread that has expanded from tropical regions to some temperate places such as Italy, France, Nepal and China [1-6]. While the transmission of CHIKV extends from Africa, to Asia and Europe, DENV transmission is active in every single continent on the globe. The primary mode of dengue and chikungunya transmission is through bites of Aedes mosquito-Aedes aegypti and Aedes albopictus.

Dengue illness causes an estimate of $50-100$ million infections annually, leading to half a million hospitalization with life threatening dengue haemorrhagic fever/ shock syndrome (DHF/DSS syndrome) [7,8]. Its causative agent, DENV, is a ssRNA positive-strand virus of

\footnotetext{
"The two authors contributed equally to the work.

${ }^{\#}$ Corresponding author.
}

the family Flaviviridae, genus Flavivirus. DENV is classified into four antigenically related but immunologically distinct serotypes, namely DENV-1, $-2,-3$ and $-4[9,10]$.

Aside from the bite of infectious mosquitoes, transmissions via dengue contaminated blood or blood products have been documented in 3 publications [11-13]. In Singapore, three patients received blood products donated by a donor who developed symptoms of dengue fever a day after donation [11]. Two of the recipients developed dengue symptoms while the third was asymptomatic and developed IgM and IgG antibodies. DENV-2 was detected by PCR assay in the donated blood products, the donor and two of the symptomatic recipients. In Hong Kong, an elderly lady acquired dengue from a blood product donated by a donor prior to the onset of dengue fever symptoms [12]. The donor was one of the six cases confirmed to be epidemiologically linked to the small Ma Wan outbreak in 2002 and DENV-1 was found in the donated blood product. The third incident occurred during the 2007 dengue outbreak in Puerto Rico [13]. A recipient of contaminated blood became febrile on the 
third day post-transfusion, subsequently developed DHF and tested positive for DENV-2 by PCR. Donor's blood was found to contain a matching virus and was one of 12 asymptomatic donors that were detected through a postoutbreak batch screening process.

Considering the incidence of dengue in endemic countries, the high proportion of asymptomatic infection (up to $87 \%$ ) and the median 5-day viremia, transfusion-associated dengue transmission may be more widespread than documented [14-16]. Predictions on the risks of accidental transfusion of dengue-infected blood products from asymptomatic carrier donors in Singapore have been reviewed $[17,18]$. Using a mathematical modeling on cases reported during the 2005 outbreak, WilderSmith and colleagues estimated the risk for dengue-infected blood transfusion to be $1.625-6 / 10,000$, assuming a ratio of 2:1 to 10:1 for asymptomatic to symptomatic infections [18]. Interestingly, S. L. Stramer et al. (2012) suggested that there could be an overestimation on the risk of viremic donations in Puerto Rico from 1995-2010 (7 per 10,000) as not all the donated products detected with viral RNA are considered infectious and associated with dengue transmission [13].

Chikungunya fever struck several islands off the Indian Ocean, Southeast Asian, and European countries causing large-scale epidemics [2-5,19-21]. The causative agent, CHIKV, is an enveloped (+) ssRNA belonging to family Togaviridae, genus Alphavirus. It causes a nonfatal, self-limiting disease characterized by abrupt onset of high fever, severe arthralgia, often associated with skin rash. In 2008, there were several outbreaks of chikungunya fever in Singapore that resulted to 718 laboratory-confirmed cases $[19,20]$. Interestingly, during the surveillance of the first outbreak, a positively-diagnosed patient developed fever only on the subsequent day [20].

Unlike dengue fever, there has been no report of transfusion-transmitted cases involving chikungunya nor documented case of contaminated blood product to date [22]. Transfusion-related transmission of CHIKV is highly possible since CHIKV has been transmitted to a health care worker drawing blood from an infected patient [23]. Concern is heightened due to the high infection rates during outbreaks and high viremia titer that can last up to six days [24]. Furthermore, at the height of the outbreak at Reunion Island in 2006, the estimated transfusion risks was estimated to be as high as 150 per 10,000 donations [21].

While dengue and chikungunya transmissions in Singapore have been controlled through a comprehensive integrated vector control program, transmission by transfusion of contaminated blood or blood products is being recognized as a threat to the current blood supply system. The current donor selection and deferral policy for ex- clusion of dengue and chikungunya infection in Singapore is primarily based on the clinical history of infection, onset of fever and travel history. However, an oversight of revealing details by donors, particular those with late symptom onset or asymptomatic cases, could lead to the contamination of blood supplies with these viruses. Therefore, in the absence of effective routine screening tests for DENV and CHIKV in Singapore, the use of a pathogen reduction system may help in ensuring safety of blood and its product.

Many studies have reported the efficacy of individual pathogen reduction system on platelets (PLTs). Here we evaluate the efficacy of 2 pathogen reduction systems concurrently to inactivate the DENV or CHIKV spiked in apheresis human platelet (APLT) concentrates. The first system, Amotosalen photochemical treatment (Amotosalen PCT, Cerus Corporation), uses amotosalen $\mathrm{HCl}$ (a photoactive compound, formerly designated as S-59) and long-wavelength UVA illumination to photochemically treat blood products. A compound adsorption device (CAD) is used to remove the residual S-59 and metabolites after illumination. The second system, Riboflavin pathogen reduction technology (Riboflavin PRT, Terumo BCT), uses riboflavin (vitamin B2), a naturally occurring, non-toxic compound, combined with UV light to substantially reduce the level of disease-causing agents in blood components. Over the storage of 5 days, the viral infectivity and PLT in vitro properties, including PLT yield, $\mathrm{pH}$ and residual S-59, were measured to assess the impact of photochemical treatments to the virus-spiked APLTs.

\section{Materials and Methods}

\subsection{Treatment of Double-Dose APLT}

A schematic diagram on the experimental design is illustrated in Figure 1. The PLTs used were obtained from donors who qualify for the donation criteria of doubledose APLT collection. APLT was used for this pathogen reduction study instead of whole blood derived PLTs as the Singapore Health Sciences Authority, Blood Services Group do not prepare pooled PLTs from whole blood donations. To facilitate comparison, double-dose APLTs were used to reduce donor-specific variability in the samples subject to the two pathogen reduction processes.

The double-dose APLT donations were randomly selected based on the fulfillment of the following quality indicators as starting source material for pathogen reduction processing. All donors of the APLTs used in this study were tested negative for past and recent dengue and chikungunya infection by using Panbio IgM capture ELISA and indirect IgG ELISA kits (Inverness Medical 


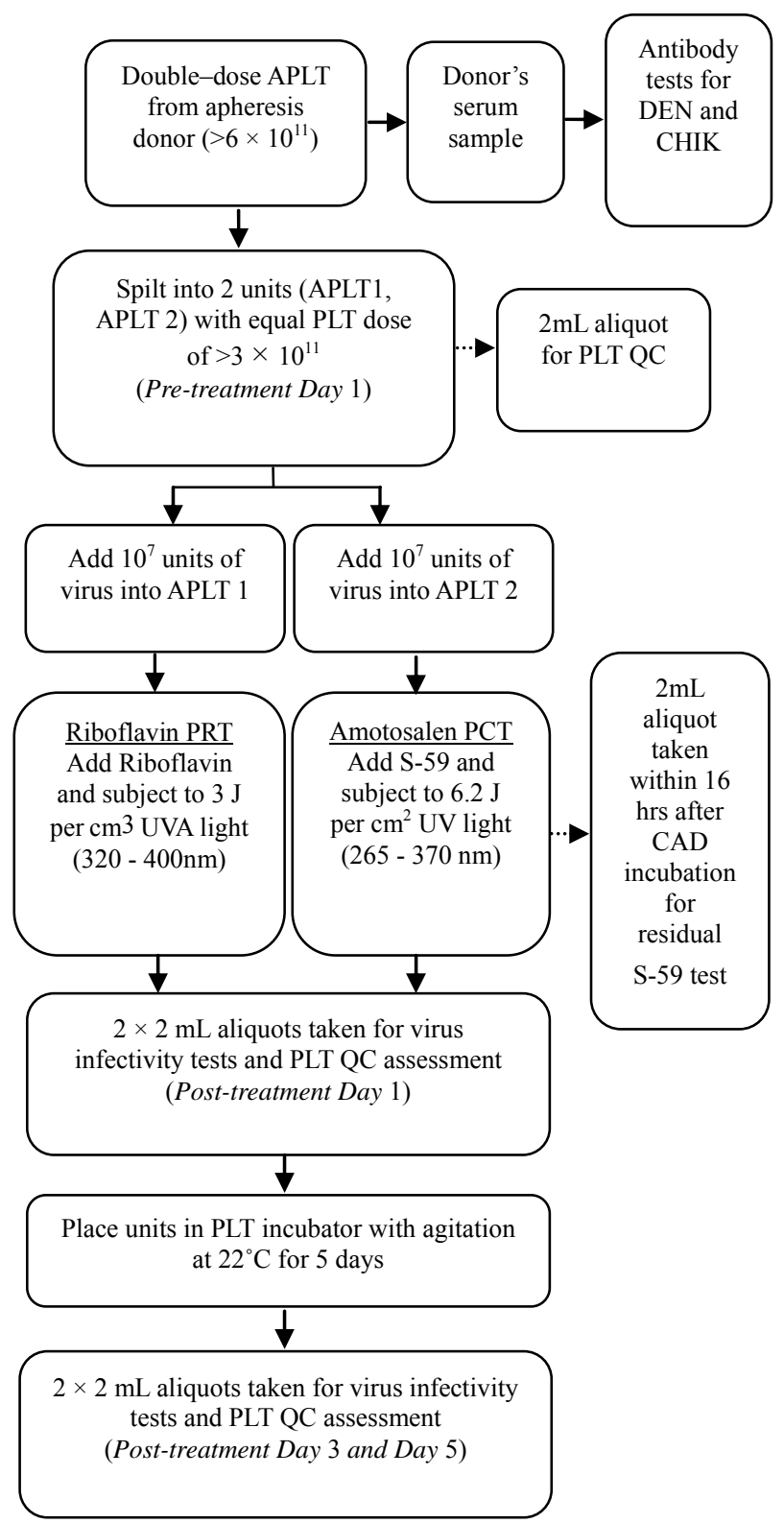

Figure 1. Schematic flow diagram showing the experimental design.

Innovations, Australia) and EUROIMMUN AG Chikungunya IgM and IgG IIFT (Lübeck, Germany), in respective.

\subsection{Cell Cultures and Virus Preparation}

DENV-2 (strain ST10) were propagated in Aedes albopictus cells (C6/36, ATCC CRL 1660) at $33^{\circ} \mathrm{C}$ for 4 5 days and titrated by plaque assay. $\mathrm{C} 6 / 36$ cultures were grown in Leibowitch L-15 medium (Invitrogen Corp., Carlsbad, CA), supplemented with 10\% heat-inactivated Fetal Calf Serum (FCS), 1\% L-glutamine solution, 100 $\mathrm{mM}$ Penicillin/Streptomycin, at $28^{\circ} \mathrm{C}$. Maintenance me- dium was similarly prepared as above but supplemented with $3 \%$ FCS.

CHIKV (strain EHI0067Y08) was propagated in Baby Hamster Kidney cells (BHK-21, Clone 15, courtesy of NITD) at $37^{\circ} \mathrm{C}$ for 3 days and titrated by plaque assay. The cells were grown and maintained in RPMI media (Sigma-Aldrich Corp., St. Louis, MO, USA), supplemented with $10 \%$ FCS, $1 \%$ L-glutamine solution, 100 $\mathrm{mM}$ Penicillin/Streptomycin, 7.5\% sodium bicarbonate, $10 \mathrm{mM}$ HEPES, at $37^{\circ} \mathrm{C}$ with $5 \% \mathrm{CO}_{2}$.

\subsection{Pathogen Reduction Treatments, Sampling and Storage of APLT Concentrates}

To test the efficacy of each pathogen reduction treatment, each APLT unit (about $260 \mathrm{mLs}$ ) was inoculated with approximately $10^{7}$ infectious units (or plaque forming unit, PFU) of DENV-2 or CHIKV in $1-2 \mathrm{~mL}$ of culture supernatant. The pre-treatment concentration was expected to be about $10^{4} \mathrm{PFU} / \mathrm{mL}$.

In units treated with the Amotosalen PCT system, APLT spiked with virus was subjected to amotosalen HCL (S-59) at $150 \mu \mathrm{mol}$ per L of APLT and exposed to 3 $\mathrm{J} \cdot$ per $\cdot \mathrm{cm}^{3}$ UVA light $(320-400 \mathrm{~nm})$ for approximately 5 min. The PCT treated APLTs were subjected to a minimum of 16 hours agitation in a storage container with Compound Adsorption Device (CAD) to remove residual S-59. In units treated with the Riboflavin PRT system, spiked APLT was treated with $500 \mu \mathrm{M}$ of riboflavin and exposed to $6.2 \mathrm{~J} \cdot$ per $\cdot \mathrm{cm}^{2} \mathrm{UV}$ light $(265-370 \mathrm{~nm})$ for approximately $10 \mathrm{~min}$. Both pathogen reduction treatments were performed according to the manufacturers' instructions. Three units of spiked APLTs were tested in each system. For each system, a unit of APLT spiked with virus and subjected to chemical treatment without UV light exposure was used as a positive control (Pos-C, $\mathrm{n}=1)$. APLTs that received no virus, and no chemical and UV treatments were referred as negative controls (Neg-C, $n=5)$. All treated APLT units were maintained at $22^{\circ} \mathrm{C}$ on a PLT incubator for 5 days. For each APLT unit, two aliquots of $2 \mathrm{~mL}$ were collected aseptically on pre-treatment Day 1, followed by post-treatment Day 1, 3 and 5, for determination of in vitro PLT quality indicators and/or for virus assays. The viral infectivity was determined by plaque assays.

\subsection{In Vitro PLT Quality Parameters}

PLT yield and $\mathrm{pH}$ were determined in all pre- and post-treated APLTs to assess the impact of inactivation processes on APLTs. PLT samples were uncapped and measured one at a time. PLT count was determined by ADVIA 120 Haematology System and TIMEPAC reagents (Siemens Healthcare Diagnostics Inc, Germany) 
on neat samples and $\mathrm{pH}$ was measured at $22^{\circ} \mathrm{C} \pm 1{ }^{\circ} \mathrm{C}$ with Accumet Basic AB15 pH meter (Fisher Scientific, USA) in an open system. The microprobe used was calibrated with $3 \mathrm{pH}$ buffer solution at $\mathrm{pH}$ 4.0, 7.0 and 10.0 before use.

\subsection{Virus Quantitation by Plaque Assay}

A series of ten-fold dilutions $\left(10^{-1}\right.$ to $\left.10^{-7}\right)$ were made with each treated and control APLT aliquot collected and assayed using BHK monolayer cells on 24-well plates. One hundred microliters of the neat or diluted aliquots were added into each well, and incubated for $1 \mathrm{hr}$ at $37^{\circ} \mathrm{C}$ with gentle rocking at $15 \mathrm{~min}$ intervals to facilitate absorption of virus and to prevent the drying out of cells. After infection, supernatants were aspirated and $1 \mathrm{~mL}$ of $1 \%$ carboxymethylcellulose (Sigma-Aldrich) was overlaid onto each well. The plate was incubated at $37^{\circ} \mathrm{C}$ for 5 days till plaque development. After fixing the cells with $20 \%$ formalin, overlaid medium was removed and cells were stained with $1 \%$ napthol blue black stain (Sigma-Aldrich). Plaques were counted and viral titer was expressed as $\log \mathrm{PFU} / \mathrm{mL}$.

\subsection{Residual S-59 Analysis}

S-59 level was assessed by Cerus Corporation using liquid-liquid phase extraction method followed by HPLC Tandem Mass Spectrometry (HPLC3408) with a detection limit of $0.125 \mu \mathrm{mol} / \mathrm{L}$.

\subsection{Statistical Analysis}

The level of virus inactivation was calculated as log reduction: $\log$ reduction $=$ Log (pre-treatment titer/posttreatment titer). If no virus was detected after treatment, the viral titer was expressed as $<1 / \mathrm{V}$ infectious units, where $\mathrm{V}$ is the total PLT volume assayed [25].

In this study, the absence of plaques for each experiment was confirmed on 4 replicate wells (total volume assayed was $0.2 \mathrm{~mL}$ ). The residual viral titer was $<1 / 0.2$ $\mathrm{PFU} / \mathrm{mL}$, which is equal to $<5 \mathrm{PFU} / \mathrm{mL}$ or $<0.70 \mathrm{log}$, for each inactivation experiment. This detection limit is equivalent to $<1300 \mathrm{PFU}$ in the total $260 \mathrm{mLs}$ of APLT.

\section{Results}

\subsection{Amotosalen PCT Reduced DENV-2 and CHIKV Inoculated in APLTs to below Detection Limits of All Assays}

A distinct reduction of DENV-2 and CHIKV was observed in all APLTs treated with Amotosalen PCT (Table 1, samples A-C, Table 1 samples E-G). Results
Table 1. Inactivation of DENV-2 and CHIKV inoculated in APLTs using Amotosalen PCT.

\begin{tabular}{|c|c|c|c|}
\hline \multirow{2}{*}{ Virus/APLTs } & $\begin{array}{c}\text { Pre-treatment } \\
\text { Day } 1\end{array}$ & $\begin{array}{c}\text { Post-treatment } \\
\text { Days } 1 / 3 / 5\end{array}$ & \multirow{2}{*}{$\begin{array}{c}\text { Extent of } \\
\text { log-reduction } \\
\text { (Pre- vs } \\
\text { post-treatment Day 1) }\end{array}$} \\
\hline & \multicolumn{2}{|c|}{$P A(L o g$ titer, $P F U / m L)$} & \\
\hline \multicolumn{4}{|l|}{ 1. DENV-2 } \\
\hline A & 3.71 & $<0.7 /<0.7 /<0.7$ & 3.01 \\
\hline B & 1.7 & $<0.7 /<0.7 /<0.7$ & 1.00 \\
\hline $\mathrm{C}$ & 2.44 & $<0.7 /<0.7 /<0.7$ & 1.74 \\
\hline $\mathrm{D}($ Pos-C) & 2.3 & $2.30 /<0.7 /<0.7$ & 0 \\
\hline \multicolumn{4}{|l|}{$\underline{\text { 2. CHIKV }}$} \\
\hline $\mathrm{E}$ & 4.4 & $<0.7 /<0.7 /<0.7$ & 3.70 \\
\hline $\mathrm{F}$ & 4.36 & $<0.7 /<0.7 /<0.7$ & 3.66 \\
\hline G & 4.45 & $<0.7 /<0.7 /<0.7$ & 3.75 \\
\hline $\mathrm{H}($ Pos-C) & 4.63 & $\mathrm{NC} / 4.15 / 3.36$ & 0.48 (vs Day 3) \\
\hline
\end{tabular}

Even in the absence of detectable IgG, variable DENV-2 concentrations were detected immediately after the virus inoculation (pre-treatment Day 1). $\mathrm{PA}=$ plaque assay PFU $/ \mathrm{mL}=$ plaque-forming units per millimetre; Pos-C $=$ positive control; $\mathrm{NC}=$ not collected

showed that the extent of log reduction of the system was as high as 3.01 and 3.75 for DENV-2 and CHIKV respectively. In this Amotosalen PCT reduction experiment, the highest levels of viruses in APLTs were $10^{3.71} \mathrm{PFU} /$ $\mathrm{mL}$ and $10^{4.45} \mathrm{PFU} / \mathrm{mL}$ for DENV-2 and CHIKV respecttively. This treatment reduced the viral load to below detection limits of plaque assay, $<5 \mathrm{PFU} / \mathrm{mL}$ or $<0.70$ $\log$.

We noticed that pre-treatment DENV-2 titers dropped after spiked into APLTs. This might be attributed to the surface receptor Fragment of Crystallization Receptor (FcR) presented on PLTs that uptake DENV-2 [26].

\subsection{Riboflavin PRT Showed Variable Degrees in Reduction of DENV-2 and CHIKV Inoculated in APLTs}

Variable degrees of DENV-2 reduction, from 0.76 to $1.58 \mathrm{log}$, were noticed in APLTs that had undergone Riboflavin PRT (Table 2, samples A-C). Only one of the APLTs (sample B), which had the lowest initial DENV-2 inoculum titer of $10^{1.88}$, showed complete viral inactivation of $1.18 \mathrm{log}$ in plaque detection assay.

Likewise to Amotosalen PCT, Riboflavin PRT showed complete inactivation of CHIKV with up to $3.73 \mathrm{log}$ reduction (Table 2, samples E-G). The positive control (sample $\mathrm{H}$ ) showed presence of infective CHIKV throughout the storage period, indicating the validity of this inactivation experiment. 


\subsection{APLTs Treated with Pathogen Reduction Systems Maintained Acceptable Yields and Quality Parameters}

The PLT yields of all test and control units were maintained between 2.63 to $3.74 \times 10^{11}$ during storage (Table 3 ), in approximate range of the AABB acceptable criteria of $3.0 \times 10^{11}$ at end of storage lifespan [27]. Our results show no significant loss of PLTs during the 5 days of storage following pathogen reduction treatment, except for one DENV-2 inoculated APLT that lost PLT concentrates of up to $22.47 \%$ following Amotosalen PCT (pretreatment Day 1 vs post-treatment Day 5, $3.69 \times 10^{11}$ vs $2.86 \times 10^{11}, \mathrm{p}=0.046$, Table 3). Other treated samples of both systems showed variable percentages of PLT loss as compared to the Neg-C $(1.68 \%$ to $3.89 \%)$ during storage.

The $\mathrm{pH}$ values of all test and control units were above 7.0 in the entire experiment (Table 4), well above the acceptable $\mathrm{pH}$ value of $\geq 6.2$ of the AABB standards for PLT recovery $[28,29]$. The initial pHs of most test units (prior virus inoculation) were higher as compared to Neg-C $(\mathrm{p}<0.026)$. Most test units had exhibited statistically significant $\mathrm{pH}$ reductions following treatments or during storage as compared to pre-treatment Day 1 ( $\mathrm{p} \leq$ 0.42 ) but overall the $\mathrm{pH}$ range is still within AABB standard.

The residual S-59 of amotosalen-treated APLTs met the $2 \mu \mathrm{M}$ absolute value $(0.5 \mu \mathrm{M}$ per test unit) as recommended by CERUS Corporation (personal communication with Melody Holtan) during the entire storage (Table 5). Following CAD treatment, the detected residual S-59 was maintained at the level much lower than the recommendation during storage.

Table 2. Inactivation of DENV-2 and CHIKV inoculated in APLTs using Riboflavin PRT.

\begin{tabular}{cccc}
\hline Virus/APLTs & $\begin{array}{c}\text { Pre-treatment } \\
\text { Day 1 }\end{array}$ & $\begin{array}{c}\text { Post-treatment } \\
\text { Days 1/3/5 }\end{array}$ & $\begin{array}{c}\text { Extent of } \\
\text { log-reduction } \\
\text { (Pre- vs }\end{array}$ \\
\cline { 2 - 3 } 1. DENV-2 & PA $($ Log titer, PFU/mL) & post-treatment Day 1) \\
\hline A & 3.46 & $1.88 /<0.7 /<0.7$ & 1.58 \\
B & 1.88 & $<0.7 /<0.7 /<0.7$ & 1.18 \\
C & 2.76 & $2.00 /<0.7 /<0.7$ & 0.76 \\
D (Pos-C) & 2.95 & $2.54 /<0.7 /<0.7$ & 0.41 \\
2. CHIKV & & & \\
E & 4.34 & $<0.7 /<0.7 /<0.7$ & 3.64 \\
F & 4.43 & $<0.7 /<0.7 /<0.7$ & 3.73 \\
G & 4.4 & $<0.7 /<0.7 /<0.7$ & 3.70 \\
H (Pos-C) & 4.52 & $4.04 / 3.46 / 3.36$ & 0.48 \\
\hline
\end{tabular}

$\mathrm{PA}=$ plaque assay $; \mathrm{PFU} / \mathrm{mL}=$ plaque-forming units per millimetre; $\mathrm{Pos}-\mathrm{C}=$ positive control.
Table 3. Modifications in PLT yield during storage period.

\begin{tabular}{ccccc}
\hline & \multicolumn{4}{c}{ Platelet count $\left(\times 10^{11}\right)$} \\
\cline { 2 - 5 } $\begin{array}{c}\text { Treatment/ } \\
\text { Virus }\end{array}$ & $\begin{array}{c}\text { Pre-treatment } \\
\text { Day 1 }\end{array}$ & \multicolumn{3}{c}{ Post-treatment } \\
\cline { 3 - 5 } & & Day 1 & Day 3 & Day 5 \\
\hline 1. Amotosalen PCT & & & \\
\hline & & $3.24 \pm 0.11$ & $3.08 \pm 0.11$ & $2.86 \pm 0.12$ \\
DENV-2 & $3.69 \pm 0.22$ & $(12.27)$ & $(16.62)$ & $(22.47)^{*}$ \\
& & $\begin{array}{c}3.37 \pm 0.12 \\
(-3.06)\end{array}$ & $\begin{array}{c}3.13 \pm 0.03 \\
(4.08)\end{array}$ & $\begin{array}{c}3.03 \pm 0.15 \\
\text { CHIKV }\end{array}$ \\
\cline { 3 - 5 } & $3.27 \pm 0.12$ & &
\end{tabular}

2. Riboflavin PRT

\begin{tabular}{|c|c|c|c|c|}
\hline DE & 366 & $\begin{array}{c}3.33 \pm 0.17 \\
(9.75)\end{array}$ & $\begin{array}{c}3.28 \pm 0.16 \\
(10.21)\end{array}$ & $\begin{array}{c}3.38 \pm 0.11 \\
\quad(7.47)\end{array}$ \\
\hline $\mathrm{CH}$ & 2 & $\begin{array}{c}2.83 \pm 0.12 \\
\quad(9.57)\end{array}$ & $\begin{array}{c}3.43 \pm 0.12 \\
(-9.57)\end{array}$ & $\begin{array}{r}3.37= \\
(-7\end{array}$ \\
\hline Neg-C & 60 & - & $\begin{array}{c}3.54 \pm 0.25 \\
(1.68)\end{array}$ & $\begin{array}{c}3.46 \pm 0.24 \\
(3.89)\end{array}$ \\
\hline
\end{tabular}

Results are expressed as mean \pm SEM, $n=3$ per treatment group, and $n=5$ for negative control (Neg-C); ( ) refers to percentage reduction as compared to first collected sample. "Compared with Amotosalen PCT DENV-2 pretreatment Day 1, $\mathrm{p}=0.046$, Student's t-Test.

Table 4. Modifications in pH during storage period.

\begin{tabular}{|c|c|c|c|c|}
\hline \multirow{2}{*}{$\begin{array}{c}\text { Treatments/ } \\
\text { Virus }\end{array}$} & \multirow{2}{*}{$\begin{array}{c}\text { Pre-treatment } \\
\text { Day } 1\end{array}$} & \multicolumn{3}{|c|}{ Post-treatment } \\
\hline & & Day 1 & Day 3 & Day 5 \\
\hline
\end{tabular}

1. Amotosalen PCT

$\begin{array}{lcccc}\text { DENV-2 } & 7.64 \pm 0.09 & 7.60 \pm 0.09 & 7.45 \pm 0.04 & 7.21 \pm 0.00^{\dagger} \\ \text { CHIKV } & 7.74 \pm 0.05^{*} & 7.64 \pm 0.03 & 7.13 \pm 0.06^{\dagger} & 7.04 \pm 0.10^{\dagger}\end{array}$

2. Riboflavin PRT

\begin{tabular}{ccccc} 
DENV-2 & $7.60 \pm 0.06^{*}$ & $7.55 \pm 0.07$ & $7.42 \pm 0.03$ & $7.12 \pm 0.12^{\dagger}$ \\
CHIKV & $7.49 \pm 0.02^{*}$ & $7.40 \pm 0.01^{\dagger}$ & $7.12 \pm 0.06$ & $7.12 \pm 0.05$ \\
3. Neg-C & $7.33 \pm 0.05$ & - & $7.37 \pm 0.03$ & $7.26 \pm 0.03$ \\
\hline
\end{tabular}

Results are expressed as mean \pm SEM, $n=3$ per treatment group, $n=5$ for untreated group. ${ }^{*}$ Compared with Neg-C Day $1, \mathrm{p}<0.022$, ${ }^{\dagger}$ Compared with respective group of pre-treatment Day $1, \mathrm{p} \leq 0.042$, Student's t-Test.

Table 5. Quantity of residual S-59 detected in the APLTs treated with Amotosalen PCT. SEM indicates standard error mean.

\begin{tabular}{cccc}
\hline \multirow{2}{*}{ Treated APLTs $(\mathrm{n}=6)$} & \multicolumn{3}{c}{ Post-CAD level : S-59 $(\mu \mathrm{mol} / \mathrm{L})$} \\
\cline { 2 - 4 } & Day 1 & Day 3 & Day 5 \\
\hline Mean \pm SEM & $0.248 \pm 0.015$ & $0.305 \pm 0.013$ & $0.370 \pm 0.019$ \\
Median & 0.23 & 0.29 & 0.35 \\
Range & $0.22-0.26$ & $0.28-0.35$ & $0.32-0.42$ \\
\hline
\end{tabular}




\section{Discussion}

The two pathogen inactivation systems have independently shown to be effective in inactivating enveloped viruses, including some flaviviruses and alphaviruses [25, 30-32]. In this comparative study, we used similar assays to demonstrate the effectiveness of these systems in inactivating two globally important viruses, DENV-2 and CHIKV, that have posed increasing threats to the blood supply $[17,18,22]$.

Donor selection and deferral based on clinical and travel history (to countries experiencing disease outbreaks) are in practice to reduce the risk of transfusiontransmitted dengue or chikungunya infection via blood supply in the absence of effective screening tests [17, $21,32]$. These strategies, however, may exacerbate the ongoing demand of blood products, particularly during disease outbreak situations. Furthermore, the significant proportion of asymptomatic DENV and CHIKV infections $[11,16,20]$ may result in the collection of contaminated blood or blood product from viraemic non-febrile donors. Accompanying the global resurgence and emergence of dengue is the increase in modal age of the cases [22], suggesting that the blood donors age group is now a susceptible population globally, and could contribute to an increased risk of DENV contaminated blood product. Altogether, these advocate the employment of pathogen reduction treatments on blood products to sustain continual supply of blood products and reduce risk of disease transmission via contaminated blood.

Interestingly, despite millions of reported cases each year, globally there have only been a few reports of blood and organ associated dengue transmission, and no report of chikungunya transmission associated with blood and organ donations. This is in contrast to the situation of West Nile virus (WNV), also a vector-borne flavivirus transmitted by mosquitoes, in the United States, where 23 patients were reported to have acquired the disease through transfusion in 2002 and where transfusion-transmitted infectious disease (TTID) continues despite implementation of nucleic acid-amplification testing (NAT) $[33,34]$. A likely explanation is that the dengue and chikungunya cases have gone unrecognized as transfusion associated, due to the challenge of epidemiological confirmation in endemic countries where the risk of acquiring dengue from the community is high. Another plausible reason for dengue is that dengue transmission in endemic areas had largely occurred among children, with most blood donors, who are adults, having acquired immunity in their childhood. The high level of seroprevalence among adult donors had in fact limited and delayed this study. A high proportion of APLTs (about 50\%) was tested positive for anti-dengue $\mathrm{IgG}$ and IgM, which interfered with the study by neutralizing the spiked viruses even before treatment (our data, unpublished).

In this comparison study, both systems showed complete inactivation to CHIKV with reductions of up to 3.73 - $3.75 \log$. While a recent report on Riboflavin PRT showed almost similar reductions of $3.5 \mathrm{log}$ activity to CHIKV [31], a higher log reduction of up to $6 \log$ had previously been documented on Amotosalen PCT [30]. Amotosalen PCT showed slightly better reductions efficacy of up to $3 \log$ for DENV-2 as compared to Riboflavin PRT. Riboflavin PRT showed up to $1.58 \mathrm{log}$ reductions to DENV-2, almost comparable to the $1.45 \log$ reductions reported by Faddy $\mathrm{H}$ et al. [35].

In this study, due to the limited availability of APLTs that are free from dengue $\operatorname{IgG}$, the other serotypes of dengue virus were not tested. Limited tests, comprising of only duplicates in separate experiments (instead of triplicates in a single experiment) were done on DENV-1 (refer supplementary table, Table S1). Two separate experiments on DENV-1 revealed a similar pathogen reduction trend as of the study on DENV-2. Amotosalen PCT showed completely inactivation of DENV-1 with $\log$ reduction of up to 4.18 while Riboflavin PRT reduced DENV-1 of up to $1.87 \mathrm{log}$. A recent study was presented by Faddy $\mathrm{H}$ et al. on the inactivation of the dengue serotypes 1, 2, 3 and 4 using Riboflavin PCT which showed $\log$ reductions of $1.28,1.45,1.71$ and 1.81 respectively [35]. Those results, consistent with our observations, demonstrate that log reduction titers obtained by the Riboflavin system are relatively independent of serotype. Taken together, both systems are likely to induce similar inactivation effect on all four serotypes of DENV.

It has been a challenge to define the required threshold for transfusion transmitted infection to occur or to determine the amount of residual pathogen in the inactivated blood product that is deemed safe for transfusion. Reports have revealed asymptomatic blood donors of Honduran could have dengue viral loads range of fewer than $3 \times 10^{4}$ to $4.2 \times 10^{4}$ copies per $\mathrm{mL}$ as quantitated by RTPCR [15] and Puerto Rico blood donors who were asymptomatic were found to contain up to $8.12 \times 10^{7}$ copies per $\mathrm{mL}$ using similar assay [14]. A recent report by Stramer SL et al. has highlighted the viral load of asymptomatic blood donors responsible for transfusiontransmitted infections [13]. During the 2007 dengue outbreak in Puerto Rico, the blood of 12 donors were found to contain DENV titers of $10^{5}-10^{9}$ copies per $\mathrm{mL}$ and viral infectivity was demonstrated in mosquito cultures. The blood implicated in the documented dengue transfusion incident had contained $1.35 \times 10^{8}$ copies per $\cdot \mathrm{mL}$ of DENV-2. While a known viral titer was reported in this transfusion-transmitted case, genomic copy numbers are 
Apheresis Platelets Suspended in Plasma

generally not equivalent to infective virus count. In a recent study of Vanlandingham DL et al., they revealed that the CHIKV viral RNA copies of $10^{8}$ per.mL is equivalent to $10^{5.5} \mathrm{PFU} / \mathrm{mL}$ (considering that only 1 of 200 genome copies are infectious) and Riboflavin PRT could not completely eliminate the risk of CHIKV infection if this high titer is found in the viremia blood [31]. Even so, the viral titer threshold to cause transfusion infection is still unclear. For other arboviruses, asymptomatic donors could have lower viral loads of 800 $\mathrm{PFU} / \mathrm{mL}$ of CHIKV [20] or $0.06-0.5 \mathrm{PFU} / \mathrm{mL}$ of WNV that has been documented to cause infection [36]. The incidence of a PLT transfusion-associated transmission of WNV was attributed to an asymptomatic donor who has an estimated viremia of $0.11 \mathrm{PFU} / \mathrm{mL}$ of virus in the implicated component. Taken together, the pathogen viral loads could vary drastically among asymptomatic individuals and the high virulence of certain pathogens could cause transfusion-transmitted infection even at minute level.

The efficiency of a pathogen inactivation technology has been constantly contested and complicated by the safety aspect and clinical efficacy of the treated PLTs [30]. Assessment of post-treatment damage to the PLTs includes the functionality and survival of transfused cells. Our study had shown that Amotosalen PCT had caused more than $20 \%$ of PLT lost in DENV-2 study. However, out of the 6 APLTs treated by Amotosalen PCT, only 3 of them had PLT count marginally below acceptable concentrate guideline of $3.0 \times 10^{11}$ after 5 days of storage, namely, 2.63, 2.80 and $2.96 \times 10^{11}$. PLT decline has been a common observation in pathogen reduction technologies. Significant PLT loss of $11 \%$ to below demanded guideline dose due to photochemical treatments had been previously reported in study of pathogen inactivation technology [37]. Besides treatment effects, platelet aggregation and the addition of culture media (and virus) might also affect PLT yield further. This is in particular that PLT aggregation by CHIKV [38] and binding of DENV-2 to PLTs surface receptor FcR [26] had been reported. Overall, our study had shown that the qualities of all post-treated APLTs were maintained at around acceptable ranges and the residual active pathogen reduction ingredient was lower than recommended.

In summary, data of this comparative study indicate that both Amotosalen PRT and Riboflavin PRT can effectively inactivate the CHIKV spiked in APLTs. Amotosalen PRT can completely eliminate DENV but Riboflavin PCT has a lower efficacy to reduce DENV in contaminated APLTs. Together with previous individual treatment studies on similar or other pathogens, this study reaffirms the usefulness of pathogen inactivation systems to ensure the safety in PLTs transfusion.

\section{Acknowledgements}

The authors are grateful to CERUS Corporation and Terumo $\mathrm{BCT}$ for the provision of pathogen reduction disposal sets and illuminator units to facilitate this pathogen reduction study. This work is funded by the National Environment Agency, Singapore. The funders had no role in study design, data collection and analysis, decision to publish, or preparation of the manuscript. The authors declare that they have no conflicts of interest relevant to the manuscript submitted to Advances Infectious Disease.

\section{REFERENCES}

[1] S. P. Sharm, "Dengue Outbreak Affects More than 7000 People in Nepal," BMJ, Vol. 341, 2010, p. c5496. doi:10.1136/bmj.c5496

[2] E. A. Gould, P. Gallian, X. De Lamballerie and R. N. Charrel, "First Cases of Autochthonous Dengue Fever and Chikungunya Fever in France: From Bad Dream to Reality!" Clin Microbiol Infect, Vol. 16, No. 12, 2010, pp. 1702-1704. doi:10.1111/j.1469-0691.2010.03386.x

[3] G. Rezza, L. Nicoletti, R. Angelini, R. Romi, A.C. Finarelli, M. Panning, P. Cordioli, C. Fortuna, S. Boros and F. Magurano, "Infection with Chikungunya Virus in Italy: An Outbreak in a Temperate Region," Lancet, Vol. 370, No. 9602, 2007, pp. 1840-1846. doi:10.1016/S0140-6736(07)61779-6

[4] K. Zheng, J. Li, Q. Zhang, M. Liang, C. Li, M. Lin, J. Huang, H. Li, D. Xiang and N. Wang, "Genetic Analysis of Chikungunya Viruses Imported to Mainland China in 2008," Virology Journal, Vol. 7, 2010, p. 8. doi:10.1186/1743-422X-7-8

[5] P. Renault, J. L. Solet, D. Sissoko,E. Balleydier, S. Larrieu, L. Filleul, C. Lassalle, J. Thiria, E. Rachou and H. de Valk, "A Major Epidemic of Chikungunya Virus Infection on Reunion Island, France, 2005-2006," The American Journal of Tropical Medicine and Hygiene, Vol. 77, No. 4, 2008, pp. 727-731.

[6] H. C. Hapuarachchi, K. B. Bandara, S. D. Sumanadasa, M. D. Hapugoda, Y. L. Lai, K. S. Lee, L. K. Tan, R. T. Lin, L. F. Ng and G. Bucht, "Re-Emergence of Chikungunya Virus in South-East Asia: Virological Evidence from Sri Lanka and Singapore," Journal of General Virology, Vol. 91, No. 4, 2009, pp. 1067-1076. doi:10.1099/vir.0.015743-0

[7] TDR/WHO, "Dengue: Guidelines for Diagnosis, Treatment, Prevention and Control," Geneva, 2009.

[8] M. E. Beatty, A. Stone, D. W. Fitzsimons, J. N. Hanna, S. K. Lam, S. Vong, M. G. Guzman, J. F. Mendez-Galvan, S. B. Halstead and G. W. Letson, "Best Practices in Dengue Surveillance: A Report from the Asia-Pacific and Americas Dengue Prevention Boards," PLOS Neglected Tropical Diseases, Vol. 4, No. 11, 2010, p. 890 doi:10.1371/journal.pntd.0000890

[9] D. J. Gubler, "Dengue and Dengue Hemorrhagic Fever," Clinical Microbiology Reviews, Vol. 11, No. 3, 1998, pp. 
480-496.

[10] S. B. Halstead, "Antibody, Macrophages, Dengue Virus Infection, Shock, and Hemorrhage: A Pathogenetic Cascade," Clinical Infectious Diseases, Vol. 11, Suppl. 4, 1998, pp. S830-S839.

doi:10.1093/clinids/11.Supplement 4.S830

[11] P. A. Tambyah, E. S. Koay, M. L. Poon, R. V. Lin and B. K. Ong, "Dengue Hemorrhagic Fever Transmitted by Blood Transfusion," The New England Journal of Medicine, Vol. 359, No. 14, 2008, pp. 1526-1527. doi:10.1056/NEJMc0708673

[12] V. W. Chuang, T. Y. Wong, Y. H. Leung, E. S. Ma, Y. L. Law, O. T. Tsang, K. M. Chan, I. H. Tsang, T. L. Que and R. W. Yung, "Review of Dengue Fever Cases in Hong Kong during 1998 to 2005," Hong Kong Medical Journal, Vol. 14, No. 3, 2008, pp. 170-177.

[13] S. L. Stramer, J. M. Linnen, J. M. Carrick, G. A. Foster, D. E. Krysztof, S. Zou, R. Y. Dodd, L. M. Tirado-Marrero, E. Hunsperger and G. A. Santiago, "Dengue Viremia in Blood Donors Identified by RNA and Detection of Dengue Transfusion Transmission during the 2007 Dengue Outbreak in Puerto Rico," Transfusion, Vol. 52, No. 8, 2012, pp. 1657-1666. doi:10.1111/j.1537-2995.2012.03566.x

[14] H. Mohammed, J. M. Linnen, J. L. Munoz-Jordan, K. Tomashek, G. Foster, A. S. Broulik, L. Petersen and S. L. Stramer, "Dengue Virus in Blood Donations, Puerto Rico, 2005," Transfusion, Vol. 48, No. 7, 2008, pp. 1348-1354. doi:10.1111/j.1537-2995.2008.01771.x

[15] J. M. Linnen, E. Vinelli, E. C. Sabino, L. H. Tobler, C. Hyland, T. H. Lee, D. P. Kolk, A. S. Broulik, C. S. Collins and R. S. Lanciotti, "Dengue Viremia in Blood Donors from Honduras, Brazil, and Australia," Transfusion, Vol. 48, No. 7, 2008, pp. 1355-1362. doi:10.1111/j.1537-2995.2008.01772.x

[16] D. S. Burke, A. Nisalak, D. E. Johnson and R. M. Scott, "A Prospective Study of Dengue Infections in Bangkok," The American Journal of Tropical Medicine and Hygiene, Vol. 38, No. 1, 1988, pp. 172-180.

[17] D. Teo, L. C. Ng and S. Lam, "Is Dengue a Threat to the Blood Supply?" Transfusion Medicine, Vol. 19, No. 2, 2009, pp. 66-77. doi:10.1111/j.1365-3148.2009.00916.x

[18] A. Wilder-Smith, L. H. Chen, E. Massad and M. E. Wilson, "Threat of Dengue to Blood Safety in Dengue-Endemic Countries," Emerging Infectious Diseases, Vol. 15, No. 1, 2009, pp. 8-11. doi:10.3201/eid1501.071097

[19] L. C. Ng, L. K. Tan, C. H. Tan, S. S. Tan, H. C. Hapuarachchi, K. Y. Pok, Y. L. Lai, S. G. Lam-Phua, G. Bucht and R. T. Lin, "Entomologic and virologic investigation of Chikungunya, Singapore," Emerging Infectious Diseases, Vol. 15, No. 8, 2009, pp. 1243-1249. doi:10.3201/eid1508.081486

[20] Y. S. Leo, A. L. Chow, L. K. Tan, D. C. Lye, L. Lin and L. C. Ng, "Chikungunya Outbreak, Singapore, 2008," Emerging Infectious Diseases, Vol. 15, No. 5, 2009, pp. 836-837. doi:10.3201/eid1505.081390

[21] C. Brouard, P. Bernillon, I. Quatresous, J. Pillonel, A. Assal, H. De Valk and J. C. Desenclos, "Estimated Risk of Chikungunya Viremic Blood Donation during an Epidemic on Reunion Island in the Indian Ocean, 2005 to 2007," Transfusion, Vol. 48, No. 7, 2008, pp. 1333-1341. doi:10.1111/j.1537-2995.2008.01646.x

[22] L. C. Ng, S. Lam and D. Teo, "Epidemiology of Dengue and Chikungunya Viruses and Their Potential Impact on the Blood Supply," ISBT Science Series, Vol. 4, No. n2, 2009, pp. 357-367. doi:10.1111/j.1751-2824.2009.01274.x

[23] P. Parola, X. de Lamballerie, J. Jourdan, C. Rovery, V. Vaillant, P. Minodier, P. Brouqui, A. Flahault, D. Raoult and R. N. Charrel, "Novel Chikungunya Virus Variant in Travelers Returning from Indian Ocean Islands," Emerging Infectious Diseases, Vol. 12, No. 10, 2006, pp. 14931499. doi: $10.3201 /$ eid 1210.060610

[24] L. R. Petersen, S. L. Stramer and A. M. Powers, "Chikungunya Virus: Possible Impact on Transfusion Medicine," Transfusion Medicine Reviews, Vol. 24, No. 1, 2010, pp. 15-21. doi:10.1016/j.tmrv.2009.09.002

[25] L. Lin, C. V. Hanson, H. J. Alter, V. Jauvin, K. A. Bernard, K. K. Murthy, P. Metzel and L. Corash, "Inactivation of Viruses in Platelet Concentrates by Photochemical Treatment with Amotosalen and Long-Wavelength Ultraviolet Light," Transfusion, Vol. 45, No. 4, 2005, pp. 580590. doi:10.1111/j.0041-1132.2005.04316.x

[26] C. H. Arturo and D. R. Smith, "Mammalian Dengue Virus Receptors," Dengue Bulletin, Vol. 29, 2005, pp. 119135.

[27] Circular of Information for the Use of Human Blood and Blood Components. In.: AABB, 2011.

[28] J. P. AuBuchon, L. Herschel, J. Roger, H. Taylor, P. Whitley, J. Li, R. Edrich and R. P. Goodrich, "Efficacy of Apheresis Platelets Treated with Riboflavin and Ultraviolet Light for Pathogen Reduction," Transfusion, Vol. 45, No. 8, 2005, pp. 1335-1341. doi:10.1111/j.1537-2995.2005.00202.x

[29] R. P. Goodrich, J. Li, H. Pieters, R. Crookes, J. Roodt and P. Heyns Adu, "Correlation of in Vitro Platelet Quality Measurements with in Vivo Platelet Viability in Human Subjects," Vox Sang, Vol. 90, No. 4, 2006, pp. 279-285. doi:10.1111/j.1423-0410.2006.00761.x

[30] S. L. Stramer, F. B. Hollinger, L. M. Katz, S. Kleinman, P. S. Metzel, K. R. Gregory and R. Y. Dodd, "Emerging Infectious Disease Agents and Their Potential Threat to Transfusion Safety," Transfusion, Vol. 49, Suppl. 2, 2009, pp. 1S-29S. doi:10.1111/j.1537-2995.2009.02279.x

[31] D. L. Vanlandingham, S. D. Keil, K. M. Horne, R. Pyles, R. P. Goodrich and S. Higgs, "Photochemical Inactivation of Chikungunya Virus in Plasma and Platelets Using the Mirasol Pathogen Reduction Technology System," Transfusion, Vol. 53, No. 2, 2012, pp. 284-290.

[32] Y. Singh, L. S. Sawyer, L. S. Pinkoski, K. W. Dupuis, J. C. Hsu, L. Lin and L. Corash, "Photochemical Treatment of Plasma with Amotosalen and Long-Wavelength Ultraviolet Light Inactivates Pathogens While Retaining Coagulation Function," Transfusion, Vol. 46, No. 7, 2006 , pp. 1168-1177. doi:10.1111/j.1537-2995.2006.00867.x

[33] L. Kightlinger, "West Nile Virus Transmission through 
Blood Transfusion-South Dakota, 2006," CDC-Morbidity and Mortality Weekly Report, Vol. 56, No. 4, 2006, pp. 76-79.

[34] L. N. Pealer, A. A. Marfin, L. R. Petersen, R. S. Lanciotti, P. L. Page, S. L. Stramer, M. G. Stobierski, K. Signs, B. Newman and H. Kapoor, "Transmission of West Nile Virus through Blood Transfusion in the United States in 2002," The New England Journal of Medicine, Vol. 349, No. 13, 2003, pp. 1236-1245. doi:10.1056/NEJMoa030969

[35] H. Faddy, J. Fryk, P. Young, D. Watterson, R. Goodrich and D. Marks, "The Effect of Pathogen Reduction Technology (Mirasol) on the Infectivity of Dengue Viruses," In: 32nd International Congress of the International Society of Blood Transfusion, Cancun, Vol. 103, 7-12 July 2012, p. 191.

[36] S. P. Montgomery, J. A. Brown, M. Kuehnert, T. L.
Smith, N. Crall, R. S. Lanciotti, A. Macedo de Oliveira, T. Boo and A. A. Marfin, "Transfusion-Associated Transmission of West Nile Virus, United States 2003 through 2005," Transfusion, Vol. 46, No. 12, 2006, pp. 20382046. doi:10.1111/j.1537-2995.2006.01030.x

[37] S. M. Picker, R. Speer and B. S. Gathof, "Evaluation of Processing Characteristics of Photochemically Treated Pooled Platelets: Target Requirements for the INTERCEPT Blood System Comply with Routine Use after Process Optimization," Transfusion Medicine, Vol. 14, No. 3, 2004, pp. 217-223. doi:10.1111/j.0958-7578.2004.00503.x

[38] M. A. Chernesky and R. P. Larke, "Contrasting Effects of Rabbit and Human Platelets on Chikungunya Virus Infectivity," Canadian Journal of Microbiology, Vol. 23, No. 9, 1977, pp. 1237-1244. doi:10.1139/m77-185

\section{Supplementary Data}

Table S1. Inactivation of DENV-1 inoculated in APLTs using Amotosalen PCT and Riboflavin PRT.

\begin{tabular}{|c|c|c|c|}
\hline \multirow{2}{*}{ Treatment/APLTs } & Pre-treatment Day 1 & Post-treatment Days $1 / 3 / 5$ & \multirow{2}{*}{$\begin{array}{c}\text { Extent of log-reduction } \\
\text { (Pre- vs post-treatment Day 1) }\end{array}$} \\
\hline & \multicolumn{2}{|c|}{$P A($ Log titer, $P F U / m L)$} & \\
\hline \multicolumn{4}{|l|}{ 1. Amotosalen PCT } \\
\hline \multicolumn{4}{|l|}{ Expt 1} \\
\hline M & 4.44 & $<0.7 /<0.7 /<0.7$ & 3.74 \\
\hline N (Pos-C) & 4.7 & $4.44 / 3.74 / 3.30$ & \\
\hline \multicolumn{4}{|l|}{ Expt 2} \\
\hline $\mathrm{O}$ & 4.88 & $<0.7 /<0.7 /<0.7$ & 4.18 \\
\hline P (Pos-C) & 4.74 & $4.72 / 3.57 / 2.30$ & \\
\hline \multicolumn{4}{|l|}{ 2. Riboflavin PRT } \\
\hline \multicolumn{4}{|l|}{ Expt 1} \\
\hline M & 4.51 & $3.78 /<0.7 /<0.7$ & 0.73 \\
\hline N (Pos-C) & 4.74 & $4.63 / 3.35 / 2.88$ & \\
\hline \multicolumn{4}{|l|}{ Expt 2} \\
\hline $\mathrm{O}$ & 5.31 & $3.44 / 2.70 / 1.70$ & 1.87 \\
\hline $\mathrm{P}(\mathrm{Pos}-\mathrm{C})$ & 4.78 & $1.83 / 2.81 / 2.70$ & \\
\hline
\end{tabular}

APLTs were inoculated with $10^{7}$ infectious units of DENV-1. The maximum number of IgG free APLTs obtained was two. Each inactivation process was evaluated in two separate experiments. Amotosalen PCT showed complete inactivation of DENV-1 with log reduction of up to 4.18. Riboflavin PRT reduced DENV-1 of up to $1.87 \log$. $\mathrm{PA}=$ plaque assay; $\mathrm{PFU} / \mathrm{mL}=$ plaque-forming units per millimetre; Pos-C $=$ positive control. 